\title{
AC 2008-535: SEVEN STEPS TO SUCCESSFUL CONTINUOUS IMPROVEMENT OF A PROGRAM
}

Swami Karunamoorthy, Saint Louis University 


\title{
Seven Steps to Successful Continuous Improvement of a Program
}

\begin{abstract}
The accrediting commissions of Applied Science, Computing, Engineering, and Technology (ASCET) are moving towards a set of harmonized criteria with identical numbering and category names. This process leads to a framework for ABET in organizing the categories of criteria across the commissions of ASCET. Individual commissions define their criteria (or create their image) within that frame. Similarly, the educational institutions in the nation also need a framework to prepare for ABET accreditation. An emphasis is given in this paper to provide a guidance for "how to" in creating a typical frame around the picture (self-study materials) while each program can decide on "what to put" in creating the picture. Also, a framework for displaying the course materials and documentation for continuous improvement of a program are discussed in this paper. These steps would serve as a viable guideline to the preparation for ABET accreditation as well as successful continuous improvement of a program.
\end{abstract}

\section{Introduction}

The program findings are in general classified as Deficiency, Weakness, Concern and Observation. A "Deficiency" would in general lead to Show-Cause (SC) for previously accredited programs and Not to Accredit (NA) for new programs or initial accreditation. A "Weakness" would in general lead to Interim Report (IR) for reportable corrective actions and Interim Visit (IV) for non-reportable corrective actions. A "Concern" in general does not affect the accreditation and the duration of accreditation would be for a full term although the corrective actions are expected at the time of Next General Review $(N G R)$. While all these findings are required to be related to a specific criteria of ABET, the finding "Observation" is in general not related to any criteria but offered for the good of a program. It does not require any corrective action.

The accreditation statistics for 2006 indicates that $90 \%$ of Applied Science programs, $48 \%$ of Technology programs, $44 \%$ of Computing programs, and 35\% of Engineering programs have received IR or IV. The weaknesses that lead to these accreditation actions are in general found in the areas of assessment of objectives, outcomes, and continuous improvement process. The seven steps presented in this paper have a great potential to minimize these weaknesses and enhance the chances for successful accreditation. Although these steps are not new, this paper brings them together with a new perception to the interpretation and application of the existing accreditation criteria.

\section{Seven Steps}

Some institutions have a department of Institutional Research and Development or a vice president or associate dean designated to provide leadership in the area of assessment and continuous improvement process. However, in many institutions it is the responsibility of the department chair or the program coordinator and program faculty members. 
Although the faculty have good intent to fulfill this responsibility, lack of support from Dean's office and lack of a typical framework for assessment process lead to inefficient and incomplete preparation for ABET accreditation.

The seven steps for continuous improvement of a program are, (1) Program Educational Objectives, (2) Program Learning Outcomes, (3) Performance Criteria, (4) Curriculum Alignment, (5) Assessment methods, (6) Evaluation methods, and (7) Continuous Quality Improvement.

\section{$\underline{\text { Step - 1: Program Educational Objectives (PEO) }}$}

ABET definition states that "Program educational objectives are broad statements that describe the career and professional accomplishments that the program is preparing graduates to achieve."

A program not only educate certain skills, knowledge and values that a student supposed to know at the time of graduation but also what he/she would become by applying or practicing those knowledge, skill and value. In simple terms, what is the purpose of the program? The answer to this question in broad statements should be developed after seeking input from constituents. As a rule of thumb, the number of objectives can be at least three and at most five.

A program in general serves the constituency of Industry and/or Government. A typical program advisory board would include members from industry, government, and society where the students would in general be employed after graduation. A regularly scheduled meeting of the Program Advisory Board at the minimum of one or two meetings per year is required. This board should be used to develop and periodically evaluate the objectives. The minutes of the meetings should be documented and preserved as evidence materials.

The program objectives must be published on the web, printed catalog, program promotional materials, and program handbook. Program handbook is one of the viable methods to disseminate the PEO to students especially the freshmen.

\section{$\underline{\text { Step - 2: Program Learning Outcomes (PLO) }}$}

ABET definition states that, "Program outcomes are narrower statements that describe what students are expected to know and be able to do by the time of graduation. These relate to the skills, knowledge, and behaviors that students acquire in their matriculation through the program."

What are the specific skills, knowledge and values a student would acquire at the end of the program? The answer to this question is given in ABET general criteria as eleven (ak) required outcomes. Since these are the minimum number of required outcomes, a program can adopt these as program learning outcomes. In addition to that if there is any distinct program specific outcomes required under the Program Criteria, they can be 
added to this list of program learning outcomes. Some of the program specific outcomes may be mapped into the general criteria outcomes of "a" through "k". The ones that stands out as distinct, they can be added to the program learning outcomes. As a rule of thumb, the number of outcomes can be at least eleven and at most fifteen.

\section{$\underline{\text { Step - 3: Performance Criteria }}$}

This step is implicit in the process and essential for assessment and evaluation. Since it is not explicit, it is a common missing link in the assessment process. Performance criteria can be defined as the identification of measurable parameters for each one of the educational objectives and learning outcomes. As a rule of thumb, the number of parameters can be at least two and at most five per outcome or objective. This step provides guidance for meaningful data collection and eliminates the chaos in this process.

"An ability to function effectively on teams" is one of the outcomes under general criteria and it is considered here for an example. Team means coming together for a common goal. Let the evaluating groups are (i) Team Members, (ii) Program Advisory Board members, (iii) Faculty members. In the beginning stage of assessment, the evaluation of team skill without any performance criteria can be represented by the average score from all three groups. The percent score is represented in a bar chart as shown below.

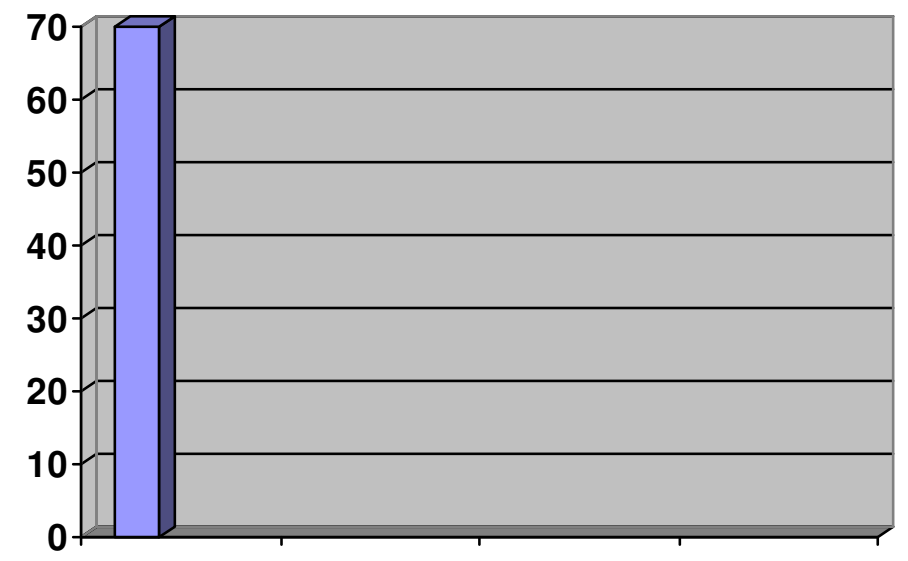

Figure 1: Team Skill Evaluation (Beginning stage)

In the developing stage of assessment, performance criteria are identified for the evaluation of team skill. A viable list of performance criteria for assessment is, (1) Listening to other team members (Team meetings), (2) Sharing the work (Team delegation), (3) Information gathering (Team contribution), and (4) Working towards the team goal (Team responsibility).

These measurable parameters help on what data need to be collected to evaluate the team skills. The average of graded percent scores by all three groups on each one of performance criteria can be represented in a bar chart as shown in Figure-2. Choosing an 
allowable percentage as bench-mark (or Rubric), the area that needs to be improved can be easily identified.

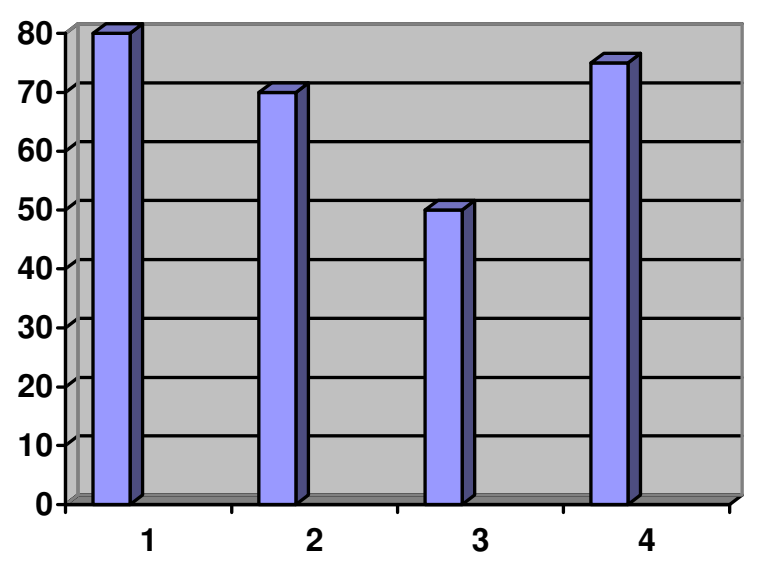

Figure 2: Evaluation of Team Skill (Developing Stage)

If a bench mark of $60 \%$ is the allowable percentage for satisfying this outcome, the performance criteria-3 can be easily identified for further improvement. This criterion is related to team contribution through gathering information. The faculty member may require the team to research the library and/or the web to find the latest available information regarding their project. The visual representation of data helps to identify where the change is required and it serves as a feedback for continuous improvement of program.

In the matured or well developed stage of assessment, in-depth or specifics in performance criteria are used for evaluation.

Performance criteria \#1: "Listening to other team members"

Specific (A): Number of team meetings

Specific (B): Minutes of the meeting

Performance criteria \#2: "Sharing the work"

Specific (A): Individual contribution

Specific (B): Knowledge of other members' contribution

Performance Criteria \#3: "Information gathering"

Specific (A): Passive (use of library, web etc.)

Specific (B): Active (personal communication with experts from academia, industry or government).

Performance Criteria \#4: "Working towards Team Goal"

Specific (A): Completion of task on time

Specific (B): Appreciation for other's work

The graded average percent scores on these specifics are given in Figure-3. 


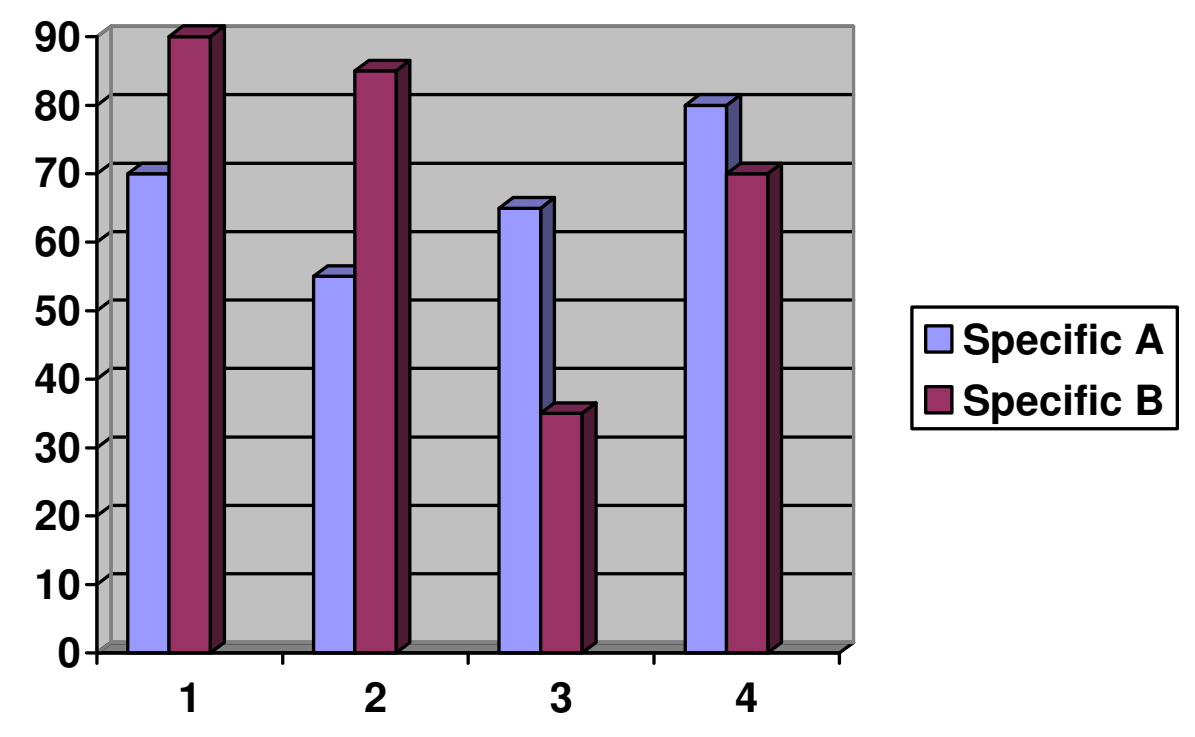

Figure 3: Evaluation of Team Skill on Specifics (Matured Stage)

Although the Figure- 2 indicates that the performance criterion \# 2 is well above the bench mark, Figure- 3 shows the weakness of this performance criterion in terms of the Specific (A). This analysis based on specifics of performance criteria provides an indepth feedback for continuous improvement of the program.

\section{$\underline{\text { Step - 4: Curriculum Alignment }}$}

Curriculum provides a prescribed path for a student to take from start to finish of a program. It needs to be aligned with the performance criteria and hence the program educational objectives, and program learning outcomes such that a student would satisfy them after completion of a program. While it would be much easier to develop a new program based on given PEO and PLO, the existing programs can be re-designed by the program faculty with their team skill. The various constraints in this process are the limit on number of credits (to enable a student to graduate within four years), university requirement, college requirement, program requirement, accreditation requirement, and flexibility (able to take elective courses) for breadth and/or depth in program. A curriculum should be optimized to meet all these requirements and carefully aligned such that it satisfies the PEO and PLO.

Each course in a curriculum should have a list of course objectives and outcomes. The course outcomes should be mapped to the program outcomes. As a rule of thumb, the number of course outcomes should be at least three and at most five. These course objectives and outcomes should be included in the Course Description provided to students enrolled in the course. The course instructor may explain these outcomes at the beginning of the course, at the end of the course, and whenever it is appropriate during the course. 


\section{$\underline{\text { Step - 5: Assessment Methods }}$}

ABET definition states that, "Assessment is one or more processes that identify, collect, and prepare data to evaluate the achievement of program outcomes and program educational objectives."

It is important to note that the definition does not have an explicit requirement of either multiple or direct assessment methods. However, some may interpret that they are implicit. Although the program findings do not depend on them, they would in general add to the strength of the assessment. A typical list of possible methods is given here including both direct and indirect methods. The list provides a choice for the selection of an assessment method and it is not required for a program to use all these methods.

Direct methods provide direct examination or observation of student knowledge or skills against measurable performance criteria for each PEO and PLO. Indirect methods are those that ascertain the opinion or self-report of the extent or value of learning experiences. These methods can be used based on appropriate performance criteria to identify, collect and prepare data. Evaluation of these data would come under the next step (Step-6).

\section{Direct Methods}

Standardized exams

Locally developed exams

Oral exams

External examiner

Portfolios

Simulations

Performance appraisal

Behavioral observations

A typical example for "Standardized exam" is the Fundamentals of Engineering (FE) examination. The graduating students may be required to take this exam during their senior year. However since it is not part of the curriculum, the logistic of enforcing it would be a challenge. In such case, "Locally developed exams" would be a viable alternative. The program faculty team can come up with a comprehensive exam covering all the essential elements in the program that can be used as graduation requirement. A past exam of FE may also be substituted for the locally developed exam.

The FE exam may also be enforced in an innovative way. Most of the engineering or technology programs have Freshmen Engineering (or Freshmen Engineering Technology) course included in their curriculum. Similarly, a course on "Senior Engineering" may be introduced in the senior year of their curriculum. This course can be offered for one or more credit hours and prepare the students for FE exam with a review of all appropriate materials. At the end of the course, past FE exam can be used for performance evaluation. The results can be used as data for assessment. Since the 
students undergo the preparation and take a mock test, they are likely to register and pass the real FE examination.

Oral-exam is a viable method especially in a laboratory course and/or design project presentations. In capstone design presentation, a practicing engineer from industry may serve as an external examiner. Students may be asked to develop course portfolios consisting of course outline, homework, quiz, test, project etc. Simulations and performance appraisals are viable methods for assessment of teams in laboratory courses as well as design courses. Behavioral observations may be viable for the assessment of ethics, diversity etc.

\section{Indirect Methods}

Senior exit survey

Junior survey

Sophomore survey

Freshmen survey

Employer survey

Alumni survey

Focus groups

Town-Hall meetings

Archival records

Surveys are efficient only when they are properly designed so that it addresses the outcomes and/or objectives clearly for meaningful response and ability to quantify the response for evaluation. Surveys that are based on qualitative opinion or related to verbal satisfaction are not considered as efficient and they should be avoided. The responses to surveys should be quantifiable.

Senior exit survey is commonly used in most of the institutions and it is a viable tool for outcome assessment. Since they are graduating, they don't directly benefit from their feedback. The surveys at Freshmen, Sophomore, and Junior level would be useful in the sense the current students can benefit from their own feedback. Employer survey and alumni survey are viable tools for the assessment of PEO. The alumni survey may be performed with graduates one year after graduation and also three years after graduation. It is also viable to survey the employers when students complete their Co-Op and/or Internship. Focus groups and Town-Hall meetings are also viable methods to assess the program outcomes. Archival records provide a history on assessment of outcomes.

\section{$\underline{\text { Step - 6: Evaluation }}$}

ABET definition states, "Evaluation is one or more processes for interpreting the data and evidence accumulated through assessment. Evaluation determines the extent to which program outcomes or program educational objectives are being achieved, and results in decisions and actions to improve the program." 
This step involves the interpretation of data and determination of the extent to which objectives and outcomes are being achieved. First the data collected in previous step with respect to appropriate performance criteria are required to be quantified. Then the data can be presented in terms of simple bar charts as shown in Step-3. Now simple statistical methods (mean, median, and mode) can be used for interpretation of data. The success of this step requires that the collected data should be relevant, accurate, and able to provide meaningful feedback. However the prerequisite for this step is the careful development of measurable parameters as performance criteria. In order to determine the extent to which a PEO or PLO are being achieved, a bench mark or a rubric should be prescribed as allowable level for meeting a specific criteria. A typical value of $60 \%$ or higher can be used as bench mark.

\section{$\underline{\text { Step - 7: Continuous Quality Improvement }}$}

This step involves the application of results obtained in previous step to effect continuous improvement of the program through a documented plan. The results should be discussed among the constituents and needed changes to improve the program should be developed as feedback. Then the program faculty should implement the changes to the program beginning from Step -1 . This process of repeating the cycle is also referred as closing the loop.

Every objective and outcome doesn't have to be measured every year. It is sufficient to demonstrate the closing of loop for every six year cycle. So, the assessment data can be collected for at most three outcomes under general criteria and one or two outcomes under program specific criteria per year. As a rule of thumb, the objectives can be assessed once in three years. In general the number of outcomes can be equally divided over a six year cycle for assessment and evaluation.

\section{Exhibit Materials}

The lack of a frame work for preparing and displaying the exhibit materials for the accreditation visit leads to ambiguity and frustration for both the visiting team and the program team. A typical model is suggested to streamline the visit process. The display materials can be grouped under three different categories as Course Portfolios, Objective Portfolios, and Outcome Portfolios.

Course Portfolios: One portfolio for each course can be developed that may include the following documents.

1. Course Outline in ABET format as given in self study report

2. Text Book and/or Handouts

3. Samples of all tests, quizzes, and final exams

4. Samples of all homework

5. Samples of lab reports for all experiments for a laboratory course

6. Sample of all projects, design reports, etc.

7. Mapping of course outcomes to program outcomes 
Objective Portfolios: One portfolio for each objective can be developed that may include the following documents.

1. Published evidence of objectives (Catalog, Web, etc.)

2. Performance Criteria

3. Assessment

4. Evaluation

5. Evidence of discussion among constituents (Minutes from Program Advisory Board meetings, a list of Board members etc.)

6. Feedback for closing the loop

7. Evidence of implementation for Continuous Quality Improvement (Updated list of objectives if applicable)

Outcome Portfolios: One portfolio for each outcome can be developed that may include the following documents.

1. Mapping of program outcomes to ABET outcomes under General Criteria as well as the outcomes under Program Specific Criteria (If the program outcomes are the same as ABET outcomes, this mapping is not necessary)

2. Performance Criteria

3. Assessment

4. Evaluation

5. Evidence of discussion among constituents (Minutes from faculty meetings, student meetings, advisory group meetings etc.)

6. Feedback for closing the loop

7. Evidence of implementation for Continuous Quality Improvement (Updated list of outcomes if applicable)

\section{Conclusions}

The process for continuous improvement of a program depends on a set of educational objectives that meets the need of program's constituencies and also consistent with the mission of the University, a set of learning outcomes, a set of measurable parameters as performance criteria, a curriculum aligned to performance criteria, collection of meaningful data based on performance criteria, evaluation of data to determine the extent to which the outcomes and objectives are achieved with appropriate rubrics, and feedback for improvement based on discussion of results with constituents. The suggested seven steps are not prescriptive for the continuous improvement process; however it provides a viable framework for individual programs to collect, analyze, and present their assessment and evaluation. The suggested framework for the display of exhibit materials would positively help both the faculty team and the ABET visiting team in the accreditation process. These frameworks would not only ensure a quality program with a continuous improvement process, but also would lead to a successful regional as well as ABET accreditation. 


\section{Bibliography}

1. ABET Criteria for 2008-09 Accreditation Cycle (Renumbered and Revised for programs under all the four commissions), ABET web site, www.abet.org/forms.shtml

2. Accreditation Statistics for the year 2006, ABET web site, www.abet.org/statistics.shtml

3. Gloria Rogers, "Assessment 101”, Community Matters, Newsletter on ABET web site, www.abet.org/newsletter.shtml 